\title{
AETIOLOGICAL PATTERN OF GASTROINTESTINAL PERFORATIONS: A PROSPECTIVE OBSERVATIONAL STUDY
}

\author{
DAS PK ${ }^{1}$, RAHMAN CMM ${ }^{2}$, RAHMAN AZM $^{3}$, SINA ND ${ }^{4}$, ISLAM MM ${ }^{5}$, SAHA KK ${ }^{6}$, MAMUN AMA $^{7}$
}

\begin{abstract}
Introduction: Peritonitis secondary to gastrointestinal perforation is one of the commonest surgical emergencies encountered all over the world. This study was done to highlight the spectrum of perforation peritonitis encountered in surgery unit of Dhaka Medical College Hospital.

Method: It was observational prospective of 100 cases of perforation peritonitis treated in our hospital. All cases of perforative peritonitis whether spontaneous, infective or neoplastic pathology were included in this study.

Results: The maximum numbers of patients were in age group between 31 to 40 years (39\%) with mean age 35 years. Male female ratio was 9:1. The most common aetiology of perforation peritonitis was peptic ulcer disease (73\%) followed by enteric fever (12\%), appendicitis (10\%), tuberculosis (3\%) and malignancy (2\%). The most common sites of perforation were in descending order of frequency - first part of the duodenum (65\%), terminal ileum (12\%), appendix (10\%), gastric antrum (9\%), jejunum (3\%) and rectum (1\%). Abdominal pain (100\%) and vomiting (81\%) were the most common symptoms while tachycardia (96\%), muscle guard and rigidity (100\%) were the common signs. Approximately 15-20\% presented late with features of shock. Mortality rate was $2 \%$ and was significantly high in patients coming hospital late.

Conclusion: Gastrointestinal perforations are one of the most common surgical emergencies. Duodenal perforations are most common. Ileal perforations secondary to enteric fever have highest morbidity. Early recognition and timely appropriate intervention is very important in reducing morbidity and mortality.
\end{abstract}

DOI: https:// doi.org/10.3329/jdmc.v29i2.51183

J Dhaka Med Coll. 2020; 29(2) : 106- 109

\section{Introduction}

Gastrointestinal perforation is a complete penetration of the wall of the stomach, small intestine or large bowel resulting in flowing of contents into the abdominal cavity causing peritonitis. The spectrum of aetiology of perforation peritonitis is different in different countries.

In our country, presentation to hospital varies depending on access availability, awareness and economy. Late cases present with generalized peritonitis with purulent or fecal contamination and varying degree of septicaemia.
It is important to know all the pattern in which a perforation peritonitis could present and the different aetiologies that lead to perforation peritonitis and the most common among them so that the decision for appropriate management of such a case can be taken at the earliest and the associated morbidity and mortality can be decreased.

Our objective was to study the aetiology and pattern of presentation of different gastrointestinal perforations based on clinical findings, radiological report, operative findings and histopathology report.

1. Dr. Prosunto Kumar Das, Assistant Professor of Surgery, Dhaka Medical College Hospital

2. Dr. Chowdhury Md. Mushfiqur Rahman, Assistant Professor, Department of Ear, Nose and Throat, Dhaka Medical College.

3. Dr. AZM Mahfuzur Rahman, Associate Professor of Surgery, Dhaka Medical College Hospital

4. Dr. Md. Nayeem Dewan, Assistant Professor of Surgery, Dhaka Medical College Hospital

5. Dr. Md. Mahmudul Islam, Assistant Professor of Surgery, Dhaka Medical College Hospital

6. Dr. Kalyan Kuman Saha, Registrar of Surgery, Dhaka Medical College Hospital

7. Dr. Abu Masud Al Mamun, Assistant Registrar of Urology, Dhaka Medical College Hospital

Correspondence: Dr. Prosunto Kumar Das, Assistant Professor of Surgery, Dhaka Medical College Hospital. Contact Number: 01714098274; E-mail: prosuntodr@yahoo.com

Received: 27-04-2020

Revision: 08-05-2020

Accepted: $21-10-2020$ 


\section{Methods}

This was a prospective study conducted in the department of surgery Dhaka Medical College Hospital. A total number of 100 cases were studied.

\section{Inclusion criteria}

- All cases presenting with signs and symptoms of perforation peritonitis

- All cases with spontaneous, infective and neoplastic pathology were included.

Exclusion criteria

- Iatrogenic perforations

- Perforations treated conservatively

- Primary peritonitis

In all selected cases, demographic profile, detailed history including time lag between onset of symptoms and presentation to hospital, and clinical examination findings and investigation reports were recorded. After adequate resuscitation, all patients underwent exploratory laparotomy in emergency setting. The pathology was sought for and treated with closure, resection with anastomosis or stoma formation. All operative findings were recorded. Post operatively patient was monitored either in ward or intensive care unit depending patients condition.

\section{Results}

Preoperative data

Gastrointestinal perforations were common in the age group of 21 to 50 years; with more than $91 \%$ being less than 50 years of age. $88 \%$ were male. Co- morbidities were mainly in the form of respiratory distress $12 \%$, hypertension $5 \%$ and diabetes mellitus $8 \%$.

Table 1

Pre-operative data of patients

Age (years)

\begin{tabular}{lc}
\hline No of cases & $(\mathrm{n}=100)(\%)$ \\
\hline$<50$ years & $91(91 \%)$ \\
$>50$ years & $09(09 \%)$ \\
Sex & \\
Male & 88 \\
Female & 12 \\
\hline
\end{tabular}

Abdominal pain (100\%) and vomiting (76\%) were the most common symptoms. Other symptoms were abdominal distension (62\%) and fever (22\%). Among physical signs, abdominal tenderness was present in all cases along with muscle guard and rigidity (100\%). Obliteration of liver dullness was present in (82\%) cases. $15-20 \%$ of patients presented with features of sock (Table II).

Table-II

Signs and symptoms on presentation

\begin{tabular}{lc}
\hline Symptoms and signs & $(\%)$ \\
\hline Abdominal Pain & 100 \\
Vomiting & 76 \\
Abdominal Distension & 62 \\
Fever & 22 \\
Tachycardia & 96 \\
Hypotension & 20 \\
Muscle Guard & 100 \\
Rigidity & 100 \\
Obliteration of liver dullness & 82 \\
\hline
\end{tabular}

Eighty two percent of the patients had pneumoperitoneum and forty two percent had air-fluid level on the x-ray; $58 \%$ had dyselectrolytaemia and $8 \%$ had serum creatinine more than 1.7 (Table III).

Table-III

Pre-operative investigation findings

Investigations $(\%)$

Pneumoperitoneum on X-ray

82

(chest \& abdomen)

Air-fluid level on erect abdominal X-ray 58

Leukocytosis

87

Hyponatraemia $(\mathrm{Na}<130 \mathrm{mEq} / \mathrm{L})$

Hypokalaemia $(\mathrm{K}<2.7 \mathrm{mEq} / \mathrm{L})$

62

Serum creatinine $(>1.7 \mathrm{mg} / \mathrm{dl})$ 
Out of 100 cases which were studied, the most common aetiology of perforation peritonitis was peptic ulcer disease, the second most common aetiology was enteric fever and other aetiologies were appendicular perforations, tuberculosis and malignancy (Table 4).

In our study, the most common site of perforation was first part of duodenum $(65 \%)$ followed by terminal ileum (12\%), appendix $(10 \%)$, pyloric part of stomach $(9 \%)$, jejunum $(3 \%)$ and rectum $(1 \%)$.

Most of the patients (74\%) came to the hospital more than 24 hours of onset of symptoms.
Table -IV

Operative data

\begin{tabular}{lc}
\hline Aetiology & $(\%)$ \\
\hline Gastro duodenal & 73 \\
Acid-peptic disease & 01 \\
Malignancy & $12 \%$ \\
Small bowel & 03 \\
Typhoid & \\
Tuberculosis & 01 \\
Large bowel & 10 \\
Malignancy & \\
Appendicular &
\end{tabular}

Table-V

Showing type of operative procedure with respect to etiology

\begin{tabular}{lccccc}
\hline Aetiology & $\begin{array}{c}\text { Primary } \\
\text { Repair }\end{array}$ & $\begin{array}{c}\text { Resection } \\
\text { and } \\
\text { anastomosis }\end{array}$ & $\begin{array}{c}\text { Appendi } \\
\text { sectomy }\end{array}$ & $\begin{array}{c}\text { Ileostomy/ } \\
\text { Colostomy }\end{array}$ & $\begin{array}{c}\text { Distal } \\
\text { gastrectomy } \\
\text { and gastro- } \\
\text { jejunostomy }\end{array}$ \\
\hline $\begin{array}{l}\text { Peptic ulcer } \\
\text { Enteric Fever }\end{array}$ & 73 & 2 & & 10 & \\
$\begin{array}{l}\text { Tubercular } \\
\text { Appendi cular }\end{array}$ & 1 & & 10 & 2 & 1 \\
Malignancy & & & & 1 & 1 \\
\hline
\end{tabular}

After optimization, exploratory laparotomy was done in all cases. In 65 cases perforation was observed on the anterior wall of the first part of duodenum. In 9 cases gastric perforation was observed which was single and was in the pyloric region. In 12 cases terminal ileal perforation was observed. Ten patients had single perforation and two patients had multiple perforations. In 3 cases, perforation was observed on the anti-mesenteric border of jejunum. Appendicular perforation was observed in 10 cases and rectal perforation in 1 case.

In all cases of peptic perforation, after cleaning of peritoneal cavity, the edges were excised to freshen the margins and the perforation was closed using Graham's patch repair technique. In terminal ileal perforation, where gut was unhealthy or where multiple perforations were present or when there was excessive soiling, ileostomy was done. In other cases, resection anastomosis or primary repair was done. In all cases of appendicular perforation appendectomy was done.

The overall mortality in the present study was $2 \%$. The causes of mortality in present series were very poor general condition of the patient at the time of admission, late reporting, septicemia, dehydration with dys-electrolytaemia.

\section{Discussion}

Perforation peritonitis is a frequently encountered surgical emergency in our country, most commonly affecting young men as compared to the studies in the west where the age range is between 45 to 60 years. In the majority of cases, the presentation to the hospital is late with well established generalized peritonitis with purulent or faecal peritonitis and varying degree of septicaemia. The most common aetiology of perforation peritonitis was peptic ulcer disease followed by enteric fever, appendicular perforation, tubercular and 
malignancy. The results of our study are in congruence with the studies of Jhobta et al, Gupta et al and Sharma et al.

Clinical presentations in the present study are well comparable with the study of Hittunen et al where all patient presented with signs of peritonitis.

The findings of $\mathrm{x}$-ray in which $82 \%$ cases had pneumoperitoneum matches with findings seen in the study of Kapoor et al (76.9\%).

The standard management of these cases is resuscitation followed by surgery which was followed in our study also. Gupta et al recommended omental patching in gastroduodenal perforations which was done in this study. In ileal perforation, Kim et al have recommended resection of small bowel in multiple typhoid perforations of the terminal ileum and exteriorization of small bowel in very sick patients.

Delayed presentation with various complications like sepsis, shock and dyselectrolytemia are important causes for increased morbidity of the patients.

\section{Conclusion}

Gastro-intestinal perforations are one of the most common surgical emergencies. The commonest aetiology is duodenal ulcer perforation. Ileal perforations have the highest morbidity and mortality. The morbidiy and mortality are higher in cases presenting late. Early presentation to hospital with early diagnosis and management is essential to reduce morbidity and mortality in patients with perforation peritonitis.

\section{References :}

1. Jhobta RS, Attri AK, Kaushik R, Sharma R, Jhobta A. Spectrum of perforation peritonitis in India - review of 504 consecutive cases. World J Emerg Surg 2006; 1:26.

2. Hittunen RK, Airaluoma MI, Mokka REM, Larmi TKI. Non traumatic perforations of small bowel. Surg. 1997;184-8.

3. Capoor MR, Nair D, Chintamani MS, Khanna J, Aggarwal P, Bhatnagar D. Role of enteric fever in ileal perforations: An overstated problem in tropics. Ind $\mathrm{J}$ Med Microbiol.2008;26:54-7.

4. Kim JP, Oh SK, Jarrett F. Management of ileal perforation due to typhoid fever. Ann Surg.1975; 181:88-91.

5. Sharma L, Gupta S, Soin AS, Sikora S, Kapoor V. Generalized peritonitis in India - the tropical spectrum. Jpn J Surg. 1991;21:272-7.

6. Batra P, Gupta D, Narang R, Rao S, Batra R. Spectrum of gastrointestinal perforation peritonitis in rural central India. J MGIMS.2013;18:44-8.

7. Agarwal N, Saha S, Srivastava A, Chumber S, Dhar A, Garg S. Peritonitis: 10 years experience in a single surgical unit. Trop Gastro.2008;2:1-6.

8. Gupta S, Kaushik R, Sharma R, Attri A. The management of large perforations of duodenal ulcer. BMC Surg.2005;5:15.

9. Noguiera C, Silva AS, Santosh JN, Silva AG, Ferreira $\mathrm{J}$, Matos E et al. Perforated peptic ulcer: main factors of morbidity and mortality. World J Surg.2003; 27:782-7.

10. Kemparaj T, Khadri S. Gastrointestinal perforations - our experience. Int Surg J.2012;28(2). 